\title{
Management of Supplemental Permanent Maxillary Lateral Incisor: A Rare Case
}

\author{
Dr Patil Anil \\ ${ }^{I}$ (Senior Lecturer, Dept. of Pedodontics and Preventive Dentistry Bharati Vidyapeeth Deemed University Dental \\ College and Hospital, Sangli, India)
}

\begin{abstract}
Supernumerary teeth or hyperdontia is defined as excess number of teeth as compared to the normal dental formula. Supernumerary teeth closely resembling normal tooth shape and morphology are often called supplemental tooth. This article describes a case of non-syndrome twelve year old boy with the presence of incisiform supplemental lateral incisor, which caused crowding and poor aesthetics. The etiology, classification and treatment alternatives for supplemental teeth are discussed.
\end{abstract}

Keywords: Hyperdontia, Incisiform supplemental teeth, Supernumerary tooth

\section{INTRODUCTION}

Supernumerary teeth or hyperdontia is defined as excess number of teeth as compared to the normal dental formula ${ }^{1}$. Supernumerary teeth may occur unilaterally or bilaterally, single or multiple and in one or both jaws. They may occur in any region of the dental arch with predilection for premaxilla with prevalence of $1.57 \%$.

Prevalence of supernumerary teeth in Caucasian population for permanent dentition ranges $0 \cdot 1$ to $3 \cdot 8 \%^{2}$. Prevalence of supernumerary teeth is lower in the primary dentition $0 \cdot 3-0 \cdot 8 \%^{3}$. The term supplemental tooth, first used by Tomes more than a century ago, refers to an extra tooth resembling a tooth of the normal series of the dentition ${ }^{4}$. Ashkenazi et al. (2007) used the term "superlative" for supplemental teeth. Different classifications on supernumerary teeth described supplemental teeth as normal, incisiform, or eumorphic ${ }^{2}$. Supplemental maxillary incisors are much less common than conical or tuberculate supernumerary teeth in this region. In a study of 112 supernumerary teeth in the anterior maxilla, only six supplemental teeth were found and no mention was made as to whether they were central or lateral incisors. ${ }^{5}$ Isolated cases of supplemental permanent maxillary central incisor have been reported though no supplemental central incisor was found in a study of 180 adult patients with supernumerary teeth in the maxillary central incisor region. ${ }^{6}$

Multiple supernumerary teeth in individuals with no other associated diseases or syndromes are rare ${ }^{5}$. The conditions commonly associated with supernumerary teeth include Cleft lip and palate, Cleidocranial dysostosis, Gardner's syndrome, Fabry Anderson's syndrome, Chondroectodermal dysplasia and EhlersDanlos syndrome ${ }^{1}$.

The etiology of hyperdontia remains unclear. One theory suggests that these teeth are formed because of local, independent, conditioned hyperactivity of the dental lamina ${ }^{5}$. Another theory states that the supernumerary tooth is formed because of dichotomy of tooth $\mathrm{bud}^{7}$. Hereditary, environmental factors are also considered important etiological factors in the occurrence of supernumerary teeth. Autosomal dominant trait has also been suggested.

Hyperdontia in the primary dentition is often overlooked because supernumerary teeth are often of normal shape, erupt normally in proper alignment; and can be mistaken for germination, fusion anomalies. ${ }^{7}$ Morphology of supernumerary teeth presenting in the permanent dentition is more variable: ${ }^{8}$

- Conical: Small peg-shaped conical tooth, most common type usually presents as a mesiodens

- Tuberculate: Larger in size than conical tooth, possesses more than one cusp

- Supplemental: Duplication of tooth in normal series

- Odontoma: Represents a hamartomous malformation

Erupted supernumerary teeth can cause aesthetic or functional problems, especially when situated in maxillary anterior region. A case of non-syndromic, supplemental type of supernumerary lateral incisor is presented.

\section{CASE REPORT}

A twelve year old boy reported to the department of Pedodontics with the chief complaint of an extra tooth in upper front jaw. There was no significant past medical history nor were any clinical signs of any recognized syndrome associated with the complaint. An extra oral examination did not reveal any abnormality.

On intraoral examination (Fig. 1,2), permanent dentition in maxillary and mandibular arches with presence of supernumerary incisor in left side maxillary arch having morphology similar to lateral incisor was 
observed. Supernumerary incisor was seen on palatal side of permanent lateral incisor, and having size similar to permanent lateral incisor. There was slight maxillary anterior crowding with labially placed and rotated lateral incisor. He had class I molar relation with marked upper arch crowding.

IOPA and maxillary occlusal radiographic examination (Fig. 3, 4) revealed complete root configuration with sound periodontium of lateral incisor and its supplemental tooth. The crown and root morphology of both left lateral incisor and supplemental tooth were identical.

Management of supernumerary tooth should be part of comprehensive treatment plan and should not be considered in isolation. Treatment depends on the type and position of supernumerary tooth and on its effect on adjacent teeth. Usually it is difficult to distinguish the normal tooth from its supplemental twin. Removal of supernumerary teeth is recommended if they are causing any pathological changes or crowding along with esthetical problem and difficulty in oral hygiene maintenance.

In the present case supplemental lateral incisor was causing difficulty in oral hygiene maintenance as well as aesthetic problems, so decision was taken to extract the supplemental tooth and align the incisors by orthodontic treatment. In the present case as both the teeth were equally formed, the tooth which is more on palatal side and causing discomfort was extracted under local anesthesia as reported by Hattab et al ${ }^{9}$ (Fig. 5). Patient was advised orthodontic treatment for the correction of crowding.

\section{DISCUSSION}

Present case is unusual as it demonstrates supernumerary lateral incisor in the anterior maxilla in patient without any syndrome. Supplemental lateral incisor is rare, only few cases having been reported in the literature till date. If a supplemental tooth is present and erupted, it may be difficult to determine which tooth is supplemental and which is part of the normal dental series. The management depends upon the type and position of these teeth and their effects on adjacent teeth. Removal of a supernumerary tooth preventing permanent tooth eruption usually results in the eruption of the tooth, provided adequate space is available in the arch to accommodate $\mathrm{it}^{10}$. Supplemental lateral incisor caused crowding and difficulty in oral hygiene maintenance thus extraction of supplemental tooth followed by orthodontic correction to establish good aesthetics and occlusion was appropriate treatment.

\section{IV.}

\section{FIGURES}

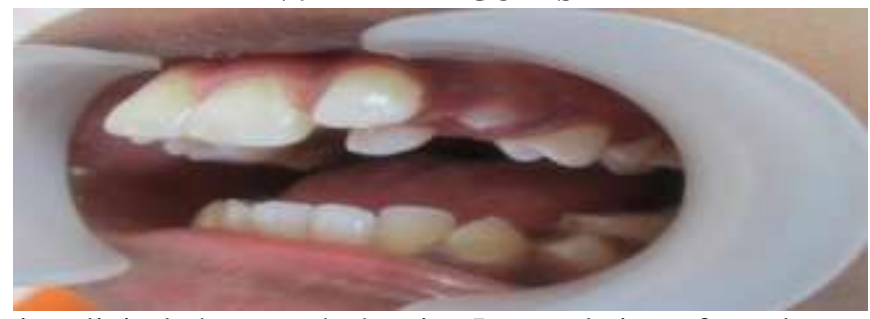

Fig. 1: Preoperative clinical photograph showing Intraoral view of supplemental lateral incisor

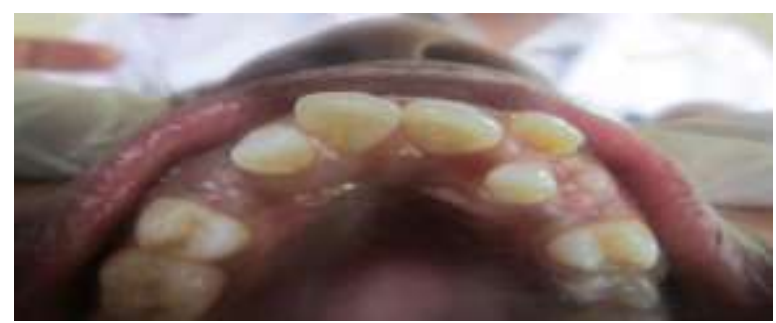

Fig. 2: Preoperative clinical photograph showing occlusal view of supplemental lateral incisor

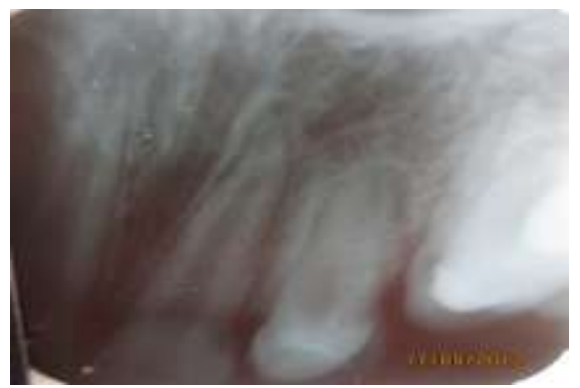

Fig. 3: Preoperative intraoral periapical radiograph of supplemental lateral incisor 


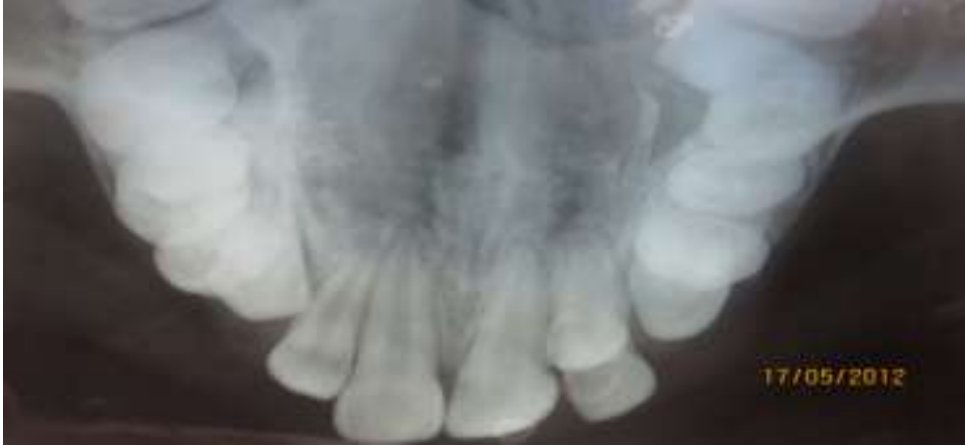

Fig. 4: Preoperative Occlusal radiograph of supplemental lateral incisor

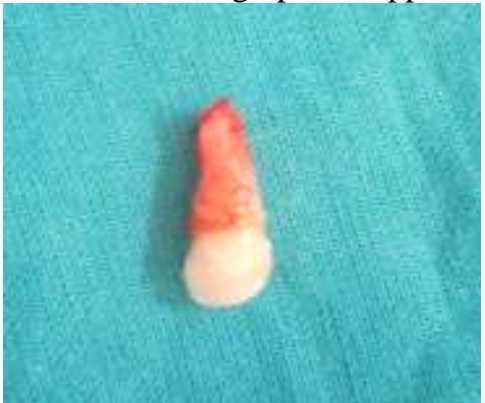

Fig. 5: Postoperative clinical photograph showing extracted supplemental maxillary lateral incisor

\section{CONCLUSION}

Extraction is not always treatment of choice for supernumerary teeth. Unerupted symptomless supernumerary teeth are sometimes best to leave in place but to be kept under observation.

\section{REFERENCES}

[1] Zhu JF, Marcushamer M, King DL, Henry RJ. Supernumerary and Congenitally absent teeth: a literature review. J Clin Pediat Dentist 1996; 20:87-95.

[2] Primosch R. Anterior supernumerary teeth-assessment and surgical intervention in children. Pediatric Dentistry 1981; 3:204-215

[3] Nasif MM, Ruffalo RC, Zullo T. Impacted supernumerary teeth: a survey of 50 cases. Journal of the American Dental Association 1983; 106: 201-204.

[4] Farmer, E.D and Lawton, F. E.; Stone's Oral and Dental Diseases, 5th ed. Edinburgh: Livingstone, 1966.

[5] Liu JF. Characteristics of premaxillary supernumerary teeth: a survey of 112 cases. ASDC Journal of Dentistry for Children 1995; 62: $262-265$

[6] Stafne EC. Supernumerary upper central incisors. Dental Cosmos 1931;73: 976-80.

[7] Humerfelt D, Hurlen B, Humerfelt S. Hyperdontia in children below four years of age: a radiographic study. ASDC Journal of Dentistry for Children 1985; 52: 121-124

[8] Garvey MT, Barry HJ, Blake M. Supernumerary teeth - an overview of classification, diagnosis and management. Journal of the Canadian Dental Association 1999; 65: 612-616.

[9] Hattab FN, Yassino M, Rawashdeh MA.Supernumerary teeth: Report of three cases and review of Literature. J Dent Child 1994:61:382-93

[10] Mitchell L, Bennett TG. Supernumerary teeth causing delayed eruption - a retrospective study. Br J Orthod 1992; 19:41-6. 